\title{
Prospects for Using Big Data in Financial Analysis
}

\author{
Igor Sadyrin, Olga Syrovatskay*, and Olga Leonova \\ ETU LETI, applied economic department, 197376 St. Petersburg, Russian Federation
}

\begin{abstract}
The ongoing digital transformation of the national economy inevitably sets the task of introducing digital technologies and tools into the practice of economic activities of organizations and enterprises. One of the areas of digitalization is Big Data technology, which in many ways is already being used in the field of finance. However, for the effective use of big data in the practice of financial analysis of economic activity, it is necessary to solve a variety of significant problems. The article discusses the promising directions of using big data in financial analysis procedures, which, being integrated into the system of forming various management decisions, can significantly increase their efficiency. The necessary elements of the financial analysis system, which, first of all, should be focused on the use of big data, are considered, as well as aspects that, when using digital technologies, can provide the maximum effect.
\end{abstract}

\section{Introduction}

An analysis of the current methodological and procedural framework for financial analysis of economic activity shows that it is far from fully consistent with modern economic, informational and technological realities, since it was developed long before the start of digital transitions. In previous years, the main direction of improving financial analysis was the automation of accounting and analytical procedures based on the use of computers and various software products. To achieve this goal, there is currently a fairly large number of software and hardware tools, the scale of which can range from a separate accounting automation program to complex management systems for large international companies. The use of integral systems for interaction with customers (CRM systems), resource management and planning systems (ERP systems) is a common business practice for many companies, but at the same time, modern management faces all the new tasks that are associated not only with storage, analysis , assessment, verification and protection of very large amounts of data, but also with the need to use new data types in the development of control solutions.

And this digitalization of the economy and the gradual transition to a new technological order open up all new opportunities and prospects in the use of digital and information technologies in analytical work. In many cases, it is necessary to use both structured and unstructured data, the sources of which can be a variety of technical and electronic devices.

\footnotetext{
**Corresponding author: syrovatskay_o.u@inbox.ru
} 
In this case, the data can have completely different formats. Economic activity is increasingly conducted in an online format and focuses on various social networks and digital platforms that act as platforms for doing business and a consumer resource.

In this regard, information and analytical systems of financial analysis should rely on the opening opportunities and one of the most promising areas of improving financial analysis and increasing its efficiency is the use of various Big Data technologies to develop new methodological foundations of financial analysis in order to form effective technological solutions for specific tasks.

\section{Goals and tasks of the study}

Study purpose is to identify promising areas for improving financial analysis based on the use of big data. In accordance with the set goal, the following tasks were solved in the article. 1. The key systemic elements of financial analysis are highlighted, in which the use of big data seems to be the most effective. 2. Analyzed the existing shortcomings and limitations that impede the use of digital technologies in the practice of financial analysis. 3. The main ways of using big data are considered and recommendations for improving and developing the methodology of financial analysis are proposed.

\section{Research methods}

The article uses theoretical research methods: analysis of literary sources and regulatory and legal framework on the issues under consideration, a systematic approach and systematization of methods and principles of financial analysis.

\section{Background and literature review}

The digitalization of the economy, as the main direction of technological and economic development, determines a qualitatively new level of work with information and data. Big data and technologies for working with them allow using powerful computing resources to operate with huge amounts of information in real time. But the avalanche-like growth of the generated data leads to the need to develop new analytical tools that allow you to structure and systematize large arrays of heterogeneous data and use them in the formation of management decisions.

In this regard, the existing analytical apparatus of financial analysis is far from fully consistent with the changed conditions. The generally accepted methodological and methodological approaches to financial analysis are considered in many foreign and domestic literary sources, including in a number of regulatory documents that determine the analysis methodology. These documents include "Methodological guidelines for the analysis of the financial condition of organizations, approved by order of the FSFR RF dated January 23, 2001 № 16" [1]. This document attempts to develop a unified methodological approach to the analysis of the financial condition of enterprises in various conditions. The methodology proposed in the order contains a rather extensive list of indicators, as well as the procedure for calculating and characterizing each of them. You can also highlight the "Rules for the conduct of financial analysis by the arbitration manager, approved by the Government of the Russian Federation of June 25, 2003 No. 367" [2]. These rules determine the principles and conditions for conducting financial analysis by the arbitration manager, the composition of the information used in the analysis and the system of indicators assessing the financial condition of crisis organizations. 
In the course of the study of literary sources devoted to the problems of financial management, it was revealed that the methods of financial analysis are well-established for a long time and are used in the financial analysis of economic activities practically unchanged [3]-[9]. Differences in the analyzed methods are of a private nature and, mainly, relate to the peculiarities of financial analysis in certain situations and conditions and do not affect the essence of the formed methodology.

\section{Research methodology and resultsрезультаты}

Following the 4 V's of big data, organizations use data and analytics to gain valuable insight to inform better business decisions. Industries that have adopted the use of big data include financial services, technology, marketing, and health care, to name a few [3].

An estimated 84 percent of enterprises believe those without an analytics strategy run the risk of losing a competitive edge in the market [4].

Currently, big data is widely used in the financial sector, but mainly in tasks related to the need to accumulate and process large volumes of statistical information, in simulation modeling, in predictive analytics, in the field of marketing and visualization of analytical data $[5]$.

At the same time, the leaders in the implementation and application of digital technologies are large companies of the national and international level, which have the necessary resources and funds for this. The use of big data in the practice of economic entities belonging to the segment of medium and, moreover, small business is difficult and expensive in terms of the possibility of independent organization of storage, processing and protection of information, as well as the development of the necessary analytical tools and data management systems. However, in the future, with the development of digitalization and the creation of national databases and digital platforms at the state level, built using cloud technologies and blockchain, many economic entities can gain access to previously inaccessible resources and use the advantages of working with Big Data in their activities.

«Public authorities in general, and central banks and financial supervisory bodies in particular, have started to collect more data to support their decisions. In addition, private commercial data providers have also clearly expanded their activities» [6].

Therefore, it is already now necessary to form the conceptual and applied foundations for the use of digital technologies in various areas of financial and economic activity, providing a systematic, integrated and structured approach to the implementation of digital technologies.

One of the most popular areas of activity, which for a long time has been based on a rather old regulatory and methodological framework, but at the same time is in dire need of updating, is the financial analysis of economic activities. The improvement of the methodology of financial analysis acquires particular relevance in the tasks of financial forecasting and planning in an unstable economic environment, the accuracy and efficiency of solving which largely depends on the ability to operate with a large amount of heterogeneous information $[4,6,7]$.

At the present stage, the financial analysis system includes several key elements:

- information base of analysis;

- analytical tools, including methods, methods, techniques and methods of analysis;

- system of absolute and relative indicators of financial condition;

- criteria (normative, recommended) limits of values of indicators, indicating a change in the type of financial condition.

Let's consider the perspectives of using big data for each element. The basis for the application of big data technology, first of all, can be an information analysis base within 
which the accumulation, structuring and storage of large volumes of various data is carried out.

Ash Gupta, chief risk officer, American Express notes that the first change that needed to be made when using big data was to improve its quality [8].

Therefore, the introduction of this technology can begin with the modernization of accounting systems. The fundamental difficulty here lies in the fact that the current and applied methods of financial analysis are based mainly on the data of the financial (accounting) statements of the organization, which by its nature is regulated and is formed in accordance with regulatory documents. By all means, financial statements are the main information source of financial analysis, but in the practice of economic activity there are a large number of off-accounting data sources that are also necessary in the implementation of management functions.

In this regard, one of the main tasks of improving the methodology of financial analysis is to modernize the approaches to determining the information base, which would take into account the availability of off-accounting data. The transformation of the information base of financial analysis should provide for the possibility of using structured and unstructured data in analytical procedures. The source of structured data is usually existing accounting or management systems (CRM, ERP, etc.). Structured data is usually stored in the form of various relational databases, which are accessed using special programming languages (SQL, Java, Piton, etc.). Structured data can be generated both by a person when interacting with various devices, and automatically mode, for example, data coming from the sales system from various reading devices, data from various sensors and tags, etc.

Unstructured or weakly structured data has an unstructured format or content, and it can be workflow data, data from social networks, data from mobile devices. Since the volume of such data can be very large, and their type is different, then working with unstructured data directly requires the use of technologies for working with Big Data. Unstructured data can also be combined into databases, for work with which content management systems (CMS) are used, the most famous of which are Hadoop, MapReduce and Streaming, which allow working with big data in real time [9].

Technological solutions that enable the potential of digital technologies have, of course, been applied for a long time. The problem is that they are not used in the field of financial analysis, since their implementation requires the solution of a number of complex problems: how to organize the storage of a large amount of data, what physical media should be used for this in order to ensure verification, backup and protection of information? To this can be added the need to monitor compliance with legislative and legal norms for working with data, for example, when working with personal data of individuals and legal entities. Solving such problems on their own for many organizations may not be possible from various points of view.

One of the possible solutions to such problems may be the creation of the necessary databases at the state level and the provision of access to them to interested users for a fee. Existing technologies already make it possible to create such digital platforms based on the Federal Tax Service for solving many practical problems, for example, in the field of lending.

Next, you need to include the ability to use different types of data in the financial analysis methodology. One of the directions of such work may be the development of new indicators of the financial condition of organizations, the calculation of which will be based on offaccounting data, but which at the same time significantly characterize some aspects of financial and economic activities or have a high predictive value.

This approach can be extremely useful for businesses that are most focused on online forms of activity, as well as interacting with consumers through various social networking resources. One of the key tasks in this case may be the building of an information system that would allow in real time to track the impact of product promotion activities and user 
actions in social networks on financial and economic indicators. For example, how does the number of "likes", comments and clicks on links affect revenue and financial results? A number of such indicators are used in the field of marketing (for example, the cost of one "click", income per client, etc.), but this practice is not common in financial analysis methods.

One of the most significant problems of financial analysis is the establishment of criterion boundaries of indicators of financial condition, reflecting the cardinal changes in this condition. It is necessary that such criterion values would reflect the specifics of the activities of organizations and at the same time would be as informative and reliable as possible. The complexity of solving such a problem is due to two circumstances.

The first is the presence of outdated regulatory documents, usually in the form of methodological recommendations, which define the procedure for calculating indicators of financial condition and provide recommended satisfactory values for a number of indicators. These methodological recommendations were developed several decades ago and in many ways do not reflect the modern practice of economic activity, and the recommended values of indicators are averaged and conservative.

The second circumstance largely follows from the first, the criterion boundaries given in the guidelines do not take into account significant differences in the activities of the analyzed enterprises, the most significant of which include: industry differences, type of production and products, property structure, capital structure, duration of the operating cycle, the structure of the cost of production, etc.

Taking into account such differences would make it possible to form a methodology for assessing the financial condition of organizations, including an interval set or some field of recommended values of indicators of financial condition, taking into account the abovementioned features of activity. The presence of such a range of values of indicators would make the assessment of the financial condition more accurate and adequate to the conditions and specifics of the activities of organizations and enterprises. At present, this task remains unsolved, mainly due to the technical complexity of its implementation. But the use of digital technologies for working with big data, such a task is becoming quite solvable. The Federal Tax Service can act as a technological platform for such a solution with the necessary resources, which accumulates the reporting data of all taxpayers required for financial analysis. At the same time, the blockchain technology, on which the operation of many other digital platforms developed by the Federal Tax Service is based, will ensure the protection and reliability of the data used.

The introduction of technologies for working with big data in financial analysis procedures presupposes the creation of an integrated and reliable management system, the fundamental architecture of which is shown in figure 1 [10]. Each dedicated structural level of the system is a functional element, and the relationships between the elements are provided by various external and internal information flows. As in all cases of working with big data, the parameters and scale of the control system will depend on the amount of data being managed, the degree of necessary reliability and stability of the system, and the required speed of working with data. 


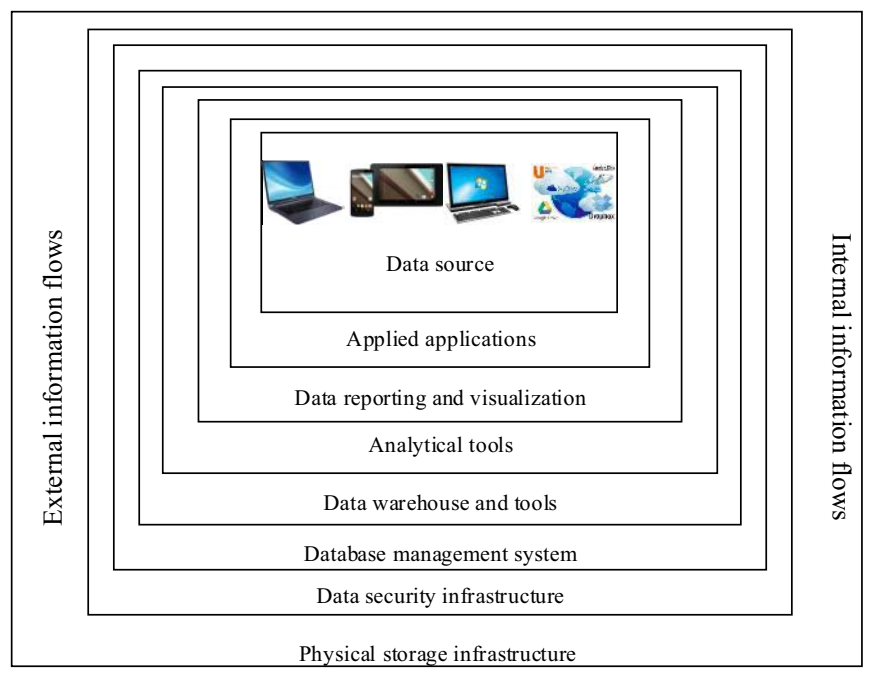

Fig. 1. Big data management architecture

The lower layer of the management system is determined by the required physical storage infrastructure of the required amount of data, taking into account ensuring uninterrupted operation in case of various system failures. This is the most expensive element of the management system, requiring constant maintenance and modernization, so building your own full-fledged level of hardware and network can be unsustainable for many organizations. Alternatively, different cloud storage options and distributed computing models may be considered.

At the same time, distributed computing models have today the most advanced encryption and data protection mechanisms, the need for which determines the next level of big data management system. The protection of confidential commercial information and personal data is a difficult practical task in modern conditions.

At the next level, you need to determine the database management system (DBMS), taking into account the specifics of the range of tasks to be solved. Relational DBMSs are most common, but more often they are used to work with large data, the advantages of which are scalability of data, their differentiation and consistency, the presence of special requests that provide intelligent access to data.

The following layers comprise various analytical tools and reporting data, the purpose of which is to scale and normalize data, as well as combine them into context-sensitive blocks for further use. The purpose of reporting data is to present the analyzed information in a convenient and visual form.

The final level is the development and use of various applications that can be adapted to specific user tasks or allow users to assemble the desired solutions from analytical blocks, like a designer.

\section{Conclusion}

Improving the methodology of financial analysis of the economic activities of organizations and enterprises in accordance with modern technological and information trends is an urgent and urgent task. As the main directions of modernization of financial analysis in the context of digitalization, the following key areas can be distinguished:

- development of updated regulatory and methodological support for financial analysis; 
- description of the information base of financial analysis, including both accounting and off-accounting sources of information and the limits of their application;

- a description of the methodology for carrying out financial analysis, including goals, objectives, analysis tools, depending on specific tasks and opportunities for using technologies for working with big data;

- formation of an updated system of indicators of financial condition based on an expanded information analysis base;

- establishment of the range of criterion boundaries of the analyzed indicators, taking into account the specifics, conditions and characteristics of the activity.

As an infrastructural support for the transformation of financial analysis, it is necessary to form the architecture of a big data management system, which includes the necessary elements discussed above, ensuring the use of complex structured information and various types of data for solving practical management problems.

\section{References}

1 Methodical instructions for analyzing the financial condition of organizations approved by the Order of the Federal Financial Markets Service of the Russian Federation of January 23, 2001 No. 16.

2 The rules for holding the arbitration managers of financial analysis, approved by the Decree of the Government of the Russian Federation of June 25, 2003 No. 367.

3 Financial technology \& automated investing automated investing. How Big Data Has Changed Finance, Febrary 10, 2021. https:/www.investopedia.com/articles/activetrading/040915/how-big-data-has-changed-finance.asp.

4 Forbes. "84\% of Enterprises See Big Data Analytics Changing Their Industries' Competitive Landscapes in the Next Year." Febrary 10, 2021. https://www.forbes.com/sites/louiscolumbus/2014/10/19/84-of-enterprises-see-bigdataana lytics-changing-their-industries-competitive-landscapes-in-the-next year/?sh=7a4f0e2417de

5 Andrey L. Bulgakov. Big Data in Finance. Journal of Corporate Finance Research / Корпоративные финансы, 2017, Vol.11, №1, p.7

6 Eurostat «Financial big data and policy work: opportunities and challenges». European Union, 2019 https://ec.europa.eu/eurostat/documents/3888793/9545860/KS-TC-19-001EN-N.pdf/aa6a7625-26ee-436d-b0c2-6b042c6abafa

7 Mr. Bill Schmarzo, CTO, Big Data Practice Dell EMC Global Services. Dr. Mouwafac Sidaoui, Associate Professor and Chair Applying economic concepts to big data to determine the financial value of the organization's data and analytics, and understanding the ramifications on the organizations' financial statements and it operations and business strategies. p.4 (28) https://infocus.delltechnologies.com/wpcontent/uploads/2017/04/USF_The_Economics_of_Data_and_Analytics-Final3.pdf

8 McKinsey. Analytics. How companies are using big data and analytics, April 21, 2016 https://www.mckinsey.com/business-functions/mckinsey-analytics/our-insights/howcompanies-are-using-big-data-and-analytics

9 Gurwitz, Joutite. Just about big data / Gurwitz Joutite, NewJent Alan, Challper Fern, Kaufman Marcia: [Translation from English].- Moscow: Eksmo, 2015. - 400 p. (Sberbank Library. T.58).

10 Leonova O. G., Sadyrin I. A., Sorovatskaya O. Yu. Financial analysis and controlling in a digital environment. St. Petersburg: Publishing House of SPbGeta "LETI", 2020. 170 p. 